Role Consensus and Supervisor Involvement

in Small Welfare Agencies

by

Frank J. Weed

University of Missouri

The relationship between a supervisor and his caseworkers in an agency has become the focus of research dealing with structural variables such as organizational size, span-of-control, and role specialization. These variables have been shown to affect the informal aspects of supervisor-subordinate relationship and the degree of role consensus between them (Thomas, 1959). One of the important influences has been the consideration of organizational size in terms of the possible interaction patterns that can emerge within a group of individuals. Researchers in the area of formal organization have demonstrated the limitations of the variable of organizational size as a predictor of other structural variables like the number of levels of hierarchy and formalization of roles, but reoganizational size has been found to be related to role consensus and other variables that emerge from informal interaction (Hal1, Hass, and Johnson, 1967; and see Hare, 1952).

Another way of dealing with the variable in large organizations has been to consider it in terms of span-of-control that a supervisor must deal with. Span-ofcontrol usually consists of an index made up of the number of supervisory levels and the size of the organization. In this case, when the span-of-control is small, the supervisor is usually characterized as dealing with subordinates in a more personal fashion. James C. Worthy (1950: 173) states the characterized relationship between supervisor and subordinate in small organizational units this way:

To employees in such units the "big boss" is not some remote, little-known, semi-mythical personage but an actual, flesh and blood individual to be disliked or liked on a basis of personal acquaintance... In small organizations. There are fewer people, fewer levels in the organizational hierarchy, and a less minute subdivision of labor. It is easier for the employee to adapt himself to such a simpler system and win a place in it.

It is not clear in Worthy'sanalysis whether size, in fact, makes the difference in the more personal supervisor-subordinate relationships; or whether role specialization makes the difference. This question is partly answered in Blau and Scotts' (1962: 168) discussion of the supervior-subordinate relationship in terms of the supervisor's span-of-control. They imply that the decrease in the span-of-control would allow a supervisor to supervise more closely, become more involved with subordinates causing the subordinates to become more dependent on their supervisor.

The above studies imply that there would be greater consensus in intrapositional role expectations in smaller organizational units because consensus tends to reflect the degree of social integration found in smaller organizational units. Consensus can be seen as the extent to which interacting individuals share common orientation and expectation for themselves and others.

Peter M. Blau in a study of a public welfare agency demonstrated that group cohesion was an important consideration in looking at supervisor-subordinate relations. He found that the more cohesive groups tended to chose their own supervisor as the best supervisor in the agency, and less cohesive groups tended oo chose another sup- 
ervisor in the agency. Blau (1960: 188) concluded his study by saying, "Perhaps the fact that a supervisor commands the respect of his workers increased the chances that cohesive ties will develop among them."

One of the characteristics often associated with small agencies, as Worthy mentioned, is that positions are often relatively unspecialized and that this may reduce social distance between supervisors and subordinates, and would not rely on the formal authority characteristic of greater role specialization.

In this study it is hypothesized that the greatest role consensus between supervisors and subordinates will be found in offices where the role specializations of the supervisor's position is low and where his involvement with the subordinates is high. In addition, it is hypothesized that in offices where the supervisor's spanof-control is small, the supervisor involvement will be high, and where the supervisor's involvement is high the group cohesion of the caseworkers will also be high.

\section{Procedure and Method}

The data for this study was gathered from eight public welfare offices in a sparsely populated, rural, midwestern state. The eight offices were selected from the thirteen possible offices which have at least two caseworkers and one welfare administrator, i.e., supervisor.

The offices range in size from eleven caseworkers and one supervisor to two caseworkers and one supervisor with the average size for the eight being 5.25 caseworkers.

The data was collected in one of the offices by a structured interview. The other seven offices were sent packets of questionnaires through the office of the chief of staff development for the State Department of Public Welfare. The questionnaires were returned to the chief of staff development and forwarded to the researcher. The cover letter stressed that this research project was not part of a state project and that the researcher would be the only person working with the questionnaire.

The results are based on the responses of 42 caseworkers and eight supervisors. All members of the offices participated in the study.

\section{Variables}

The first variable to be considered is the span-of-control. In this research the number of caseworkers in the organization is used as a measure. The offices are simple organizational structures with only one supervisor for a given number of caseworkers so that the span-of-control varies directly with the number of caseworkers.

The second variable refers to the supervisors' use of regular formalized staff meetings to coordinate the office operation. This variable is referred to as the use of formal communication mechanisms which are common in welfare agencies. This variable was measured by the question, "How often do you have formal staff meetings?" and four alternatives were presented ranging from twice a week to once a month.

The third variable is office cohesion which is defined as the prevalence of integrative bonds among group members. This has generally been measured by the proportion of ingroup choices. 
Two sociometric questions were used which asked who caseworkers like to associate with in the office. In order to get a measure of group cohesion that reflects a somewhat even distribution of choices, the proportion of caseworkers receiving two or more choices is used as an index of cohesion.

The fourth variable is supervisor involvement which refers to the degree to which the supervisor is involved with his caseworkers and integrated into the caseworker's group. Supervisor inovlvement consists of the percentage of total sociometric choices that the supervisor received from his caseworkers.

The fifth and sixth variables deal with the supervisors' and the caseworkers' orientation towards supervision. The variable of close supervision refers to the kind of supervision that entails an intensification of face-to-face direction of the worker. For the most part both worker and supervisor see close supervision involving a "strictness" about the caseworker's work. Subordinates saw their supervisor as supervising them "closely," and in addition, close supervision requires that the supervisor make use of agency policies and procedures to control his subordinates (B1au and Scott, 1962).

To measure this variable, the supervisors were asked three questions:

1) Do you feel that it is your job to be strict about your caseworker's work performance?

2) Do you feel that you should supervise your caseworkers closely?

3) Do you feel it is an important part of your job to interpret policies for your caseworkers that may not be clear in a situation?

The supervisor checked one of the boxes along a five point scale ranging from "definitely" (5) to "never" (1); or "quite important" (5) to "not important" (1). The sum total for the three questions was used as the supervisor's rating of close supervision.

The caseworker's rating of close supervision was made up of three questions which are designed to be conceptually consistent with the definition and the supervisor's items. To measure this variable the caseworkers were asked three questions:

1) Do you feel that your supervisor is strict about your work performance on the whole?

2) Does your supervisor supervise you closely?

3) Is your supervisor an expert on the laws and policies pertaining to your agency?

The caseworkers checked one of the boxes along a five point scale ranging from "definitly" (5) to "never (1). The sum of these three items was used as the measure of close supervision. 2

The seventh variable is role specialization. If the supervisors carried caseloads in addition to their administrative duties they were said to have a less specialized role compared to those supervisors who did not carry a caseload. The item was scored as a dichotomous variable with supervisors without a caseload having the highest score. The supervisors that carried a caseload had about half the number of cases that a regular caseworker had. 


\section{Results}

The correlation coefficients are presented in Table 1 for the seven variables used in the study. First, the relationship between span-of-control and the use of formal communication by the supervisor is a moderately good positive relationship $(r=+676)$. It appears here that the greater number of subordinates requires a greater effort on the part of the supervisor to coordinate activities regardless of the cohesion of the office. The relationship between formal communication and cohesion when the span-of-control is controlled for is reduced to $r_{23.1}=+.0663$ indicating that span-of-control is the independent variable.

\section{Table 1}

\begin{tabular}{lccccccc} 
& 1. & 2. & 3. & 4. & 5. & 6. & 7. \\
\hline 1. Span-of-control & 1.00 & +.676 & -.805 & -.916 & +.309 & -.345 & +.539 \\
\hline 2. Formal Communication & & 1.00 & -.515 & -.521 & +.100 & -.028 & +.233 \\
\hline 3. Cohesion & & & 1.00 & +.936 & -.564 & +.454 & -.706 \\
\hline 4. Supervisor Involvement & & & & & & & \\
\hline
\end{tabular}

5. Superviosrs' rating of Supervision

$1.00-.404+.688$ 6. Caseworkers' rating of
Supervision

$1.00-.655$

7. Role Specialization

1.00

Second, the variable of span-of-control, work group cohesion, supervisor involvement, and role specialization will be dealt with as a group of variables. Taking the relationships between span-of-control, supervisor involvement and cohesion in Table 1, the relationship between span-of-control and cohesion $(r=-.805)$ is negative indicating that the smaller work groups are more cohesive, but this relationship is contingent on the supervisor's involvement in the work group. When the effect of the supervisor involvement is controlled for, the relationship between the span-ofcontrol and cohesion is reduced to $\mathrm{r}_{13.4}=+.3885$.

The relationship between span-of-control and supervisor involvement, and between supervisor involvement and cohesion indicated that in instances when the supervisor has fewer caseworkers to supervise, he becomes more involved with them and that the caseworkers become a more cohesive group. The relationship between span-of-control and cohesion is then conditionally dependent on supervisor involvement with caseworkers

The role specialization of the supervisor's position is related to the supervisor's involement with his subordinates $(r=+781)$. The greater the role specialization of the supervisor's position, the less is his involvement with caseworkers. This relationship is somewhat independent of other factors. The relationship between cohesion and role specialization $(r=+706)$ is dependent on the supervisor's involvement as seen in the first order partial correlation $r_{37.4}=+.1137$. It can also be 
demonstrated that the span-of-control is not a factor in the relationship between supervisor involvement and the role specialization of the supervisor. The first order partial $r_{47.1}=-.8505$ indicates that the supervisor's involvement with the caseworker is more a function of his role specialization than the span-of-control.

The relationships between these four variables would indicate that the span-ofcontrolfound in the small agencies along with the role specialization of the supervisor's position are the primary determinates of the degree of involvement the supervisor has with his subordinates and the cohesion of the agency. When the supervisor shares some of the problems of casework with this subordinates and only has a few subordinates to supervise, he tends to rely on an informal pattern of control which is characteristic of well integrated groups.

Third, the two ratings of close supervision in Table 1 have opposite signs when they are correlated with cohesion, supervisor involvement, and role specialization of the caseworker. The caseworker's rating of close supervision and the supervisor's rating of close supervision are not highly correlated $(r=+.404)$.

The relationship between the caseworker's rating of close supervision and cohesion $(r=+.454)$, and supervisor's rating of the close supervision and cohesion $(r=+.564)$ can be shown to be contingent upon the role specialization of the supervisor's position. The first order partial correlations are $r_{36.7}=+.029$ and $r_{35.7}=-.1523$ respectively. The relationship between the caseworker's rating of close supervision and supervisor involvement $(r=+.688)$ can be shown to be contingent upon the role specialization of the supervisor. The first order partial correlations are $\mathrm{r}_{46.7}=+.119$ and $r_{45.7}=+.035$ respectively.

Table 2

Supervisors Rating of Supervision
Caseworkers Rating of Supervision

$\begin{array}{llr}\bar{x}=12.8 & \bar{x}=10.56 & 2.24 \\ \bar{x}=10.66 & \bar{x}=11.83 & -1.17\end{array}$

Low Specialization

$\star$

The difference between means on the supervision index are not significant at the .05 level.

The results from Table 1 show that supervisors with the more specialized role see themselves as supervising the caseworker more closely, but that his caseworker see the supervisor as supervising less closely. The greater agreement in the supervisor's role is found in offices with the less role specialization in the supervisor's position. Table 2 gives the mean rating for offices with high role specialization and low specialization of the supervisor's position. The smallest difference, i.e., the greatest consensus, is found in the offices with low role specializaioon and for that matter, offices with the greater supervisor involvement with caseworkers. This finding supports the previous finding that the role specialization of the supervisor position creates a social distance between the supervisor and the caseworkers. When the supervisor is sharing in the caseworker's problems there is closer agreement between the supervisor and the subordinate on the supervisor's role. 
pan-of-control are the major determinants of role consensus and supervisor involveent. In agencies with a greater span-of-control and with greater role specialization $f$ the supervisor's position, there will be a greater social distance between the upervisor and his staff. This is reflected in three of the findings. First, in gencies where the supervisor has the greatest span-of-control he will rely more eavily on formal communication patterns to coordinate the agencies' activities. By aving frequent staff meetings, the supervisor treats his staff as a group rather han dealing with a large number of problems individually; but in doing this the upervisor, to some degree, sets himself apart from the staff members.

Secondly, the supervisors in agencies with a smaller span-of-control and less ole specializationbecome more involved with their caseworkers and the office on the hole is a more cohesive group. The supervisors in agencies with the greater spanif-control remained somewhat more aloof and were less involved with subordinates. The findings of this study indicate that when a supervisor is sharing directly in the iame problems that the caseworkers have, he becomes more involved in their group, and :he caseworkers become a more cohesive group because of it. The supervisor shares :hese problems by carrying a caseload himself, thus reducing the task differentiation jetween himself and his subordinates.

Thirdly, the supervisors who have the greatest role specialization tend to rate themselves as supervising more closely than supervisors in agencies that have less cole specialization. This would indicate that when there is greater social distance setween the supervisor and subordinates, the supervisor puts a greater emphasis on closer surveillance of subordinates. The fact that the caseworkers react in the opposite fashion reflects the kind of surveillance found in close supervision. Caseworkers in offices with the greatest role specialization tended to rate their supervisors low on the close supervision index compared to caseworkers in offices with high role specialization. The difference in the relationships between the two ratings of close supervision can be explained by the fact that supervisors in agencies with low role specialization used a more personal form of surveillance causing the caseworker to feel more closely supervised.

The greater involvement of the supervisor, and the greater cohesion in the offices that have low role specialization causes greater role consensus. Role consensus in this case is the product of the interaction between the supervisor and his subordinates in a well integrated org anization unit.

\section{Footnotes}

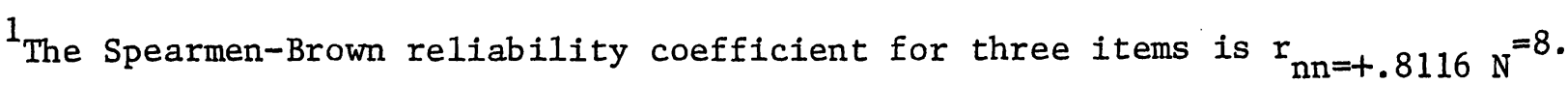

2 The Spearman-Brown reliability coefficient for three items is $\mathrm{r}_{\mathrm{nn}=.+7760 \mathrm{~N}}=42$.

3 This relationship is similar to Blau's observation of supervisors in an employment office.

References

Blau, Peter

1960 "Structural Effects." American Sociological Review 25 (Apri1).

1962 and W. Richard Scott. Formal Organization. San Francisco: Chandler Publishing

Company. 
1967 Dynamics of Bureaucracy. Chicago: University of Chicago Press.

Hal1, Richard H., J. Eugene Hass, and Norman J. Johnson

1967 "Organizational Size, Complexity and Formalization." American Sociological Review 32 (December): 903-11.

Hare, Paul A.

1952 "A Study of Interaction and Consensus in Different Size Groups." American Sociological Review 17 (June): 261-7.

Thomas, Edwin J.

1959 "Role Conceptions and Organizational Size." American Sociological Review 31 (Apri1): 179-91.

Worthy, James C.

1950 "Organizational Structure and Employee Morale." American Sociological Review 15 (April). 